\title{
Intrabronchial metastases from renal carcinoma with recurrent tumour expectoration
}

\author{
A G JARIWALLA, A SEATON, R J M McCORMACK, A GiBBS, I A CAMPBELL \\ AND B H DAVIES
}

From Llandough Hospital, Cardiff and City Hospitai, Edinburgh

\begin{abstract}
Three patients are described who presented to their doctors with a history of coughing up pieces of tissue. These took the form of large bronchial casts and consisted of intrabronchial deposits of clear cell carcinoma. In one patient the pulmonary symptoms preceded the finding of a primary renal carcinoma by four years. The other two patients had undergone nephrectomy for renal carcinoma 13 and four years previously. Expectoration of intrabronchial tumour should alert the physician to the possibility of metastasis from clear cell carcinoma of the kidney.
\end{abstract}

In thoracic medical practice it is rare for a patient to present his doctor with the material from which a histological diagnosis can be made without the need to submit to biopsy. We describe three such patients, all of whom expectorated tumour tissue and all of whom had intrabronchial metastasis from renal carcinoma.

\section{Case reports}

\section{PATIENT 1}

A previously healthy 34-year-old man was admitted to hospital in July 1969 with right-sided pleurisy, cough, and dyspnoea after an influenzalike illness. On three separate occasions he had expectorated pieces of "pink meaty tissue" approximately $1 \mathrm{~cm}$ long. His chest radiograph showed a small right pleural effusion and opacities in the right lower zone thought to represent mucoid impaction. Bronchoscopy was normal and he made a spontaneous recovery both clinically and radiographically. In December 1969 he expectorated more material and was found to have a cavity in the right lower lobe on a chest radiograph. At bronchoscopy a mass was seen to be obstructing the right lower lobe bronchus and on biopsy this showed amorphous eosinophilic material overlying a mass of granulation tissue, deep to which was a small focus of clear cell carcinoma. Right lower lobectomy was performed

Address for reprint requests: Dr Anthony Seaton, Director, Institute of Occupational Medicine, 8 Roxburgh Place, Edinburgh EH8 9SU. and the lobe was found to contain in intrabronchial tumour obstructing the medial basal bronchus with a resulting mucocele. There were two other lesions approximately $1 \mathrm{~cm}$ in diameter in the lobe and a tumour deposit was found in a hilar node. All were clear cell carcinoma (fig 1).

Apart from one episode of haemoptysis in 1971, when the chest radiograph was normal, the patient remained well until 1973 . He then presented with fever, dyspnoea, and haemoptysis. His urine contained some red blood cells and albumin and his chest radiograph showed a round lesion in the left lung, a left pleural effusion, and a fracture of the left seventh rib. He was found to have a left hypernephroma and was treated by nephrectomy and given medroxyprogesterone. Over the next eight months he continued to have recurrent tumour expectoration, the pieces being confirmed microscopically as containing clear cell carcinoma. On each occasion expectoration was preceded by a period of fever and malaise. Bronchoscopy in October 1973 showed pedunculated tumour in the right upper and left upper and lower lobe bronchi. He received palliative radiotherapy to his right lung and survived three more years, dying in December 1976 of cerebral metastases.

\section{PATIENT 2}

In 1972, a 61-year-old hairdresser underwent a nephrectomy for carcinoma of the right kidney. In January 1975 he was admitted to hospital because of severe angina. A chest radiograph at that time showed an opacity of the anterior segment 


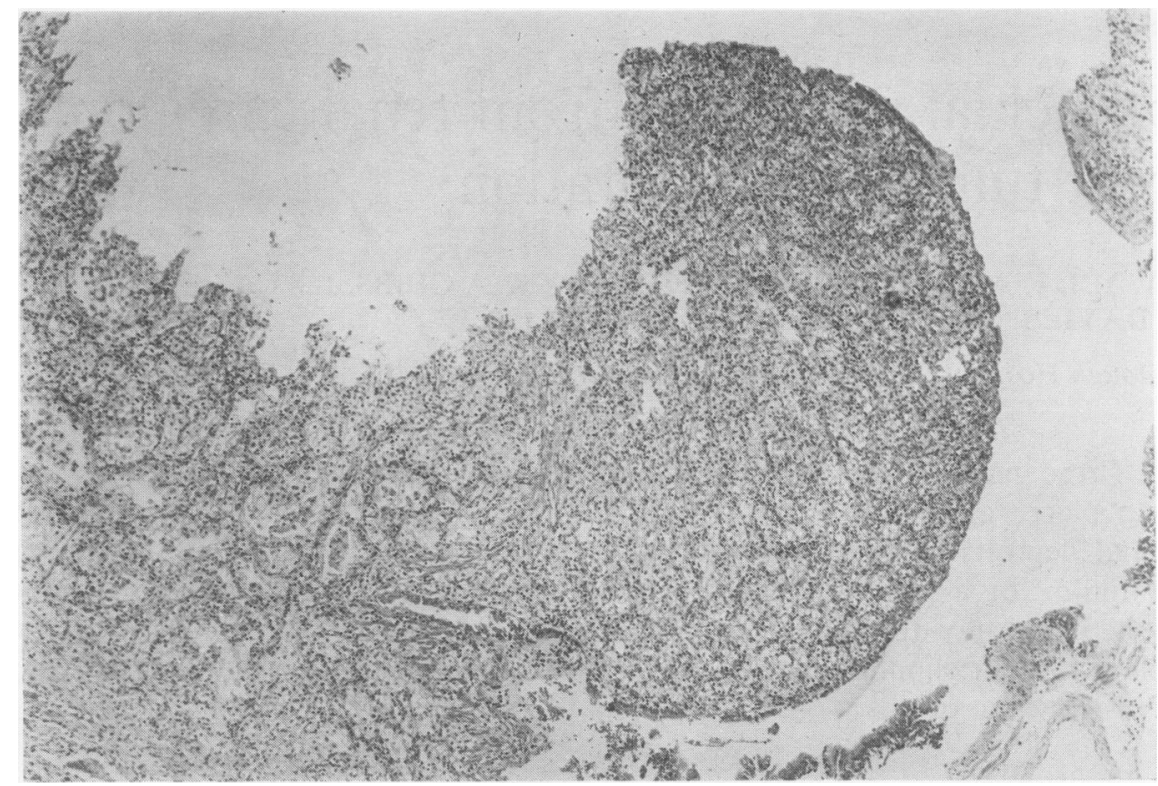

Fig 1 Patient 1 Biopsy of a nodule showing predominantly intrabronchial clear cell carcinoma. $H$ and $E$, original magnification $\times 56$.

of the right upper lobe. At bronchoscopy there was irregular tissue in the orifice of the right upper bronchus. The pathologist described the biopsy as showing much necrotic tissue and some cells "suggestive of malignancy." It was accepted that the patient had a tumour but it was thought that surgical treatment should first be directed to the management of his severe coronary artery disease. In January 1975 triple coronary bypass grafts were placed and a smooth recovery followed. One month later he had a right upper lobectomy. There was consolidation in the anterior segment but no palpable tumour in the bronchus. Routine bronchoscopy at the end of the procedure showed a plug of what appeared to be tumour tissue lying loose in the right lower bronchus. The pathologist described anaplastic carcinoma in the resected right upper lobe bronchus and also suspicious cells in the plug aspirated from the right lower lobe bronchus. Thereafter the patient was well but in June 1977 he coughed up some material which he described to the general practitioner as looking like tripe. Bronchoscopy showed no abnormality other than the lobectomy appearances. The patient remained well and then in June 1978, three and a half years after his lobectomy, he coughed up a 2 in long branching string-like structure which the practitioner thought might be a cast of a bronchus. $\mathrm{He}$ sent it to the pathologist, who reported necrotic material containing large undifferentiated carcinoma cells of clear cell type. Bronchoscopy now showed a tongue of yellowish tissue protruding from the orifice of the left upper lobe bronchus and extending up the main bronchus. The tissue contained the same type of carcinoma cells and it was only now appreciated that the original renal tumour, the two pulmonary tumours, and the expectorated tumour all had the same histology and that we were dealing with pulmonary metastases from a primary renal carcinoma. In August 1978 he had a left upper lobectomy with sleeve resection of the main bronchus. Again free intrabronchial tumour was sucked out of the main bronchus during the operation and again the same histology was demonstrated. When seen recently, eight years after nephrectomy and five years after his first lobectomy, the patient was well with no evidence of recurrent tumour.

PATIENT 3

In 1964 a 43-year-old man underwent left $\stackrel{\mathscr{Q}}{\rightleftharpoons}$ nephrectomy for hypernephroma. He remained well and his chest radiograph remained clear until 1977 when he developed haemoptysis. He had a raised blood sedimentation rate $(82 \mathrm{~mm}$ per hour) and gamma glutamyl transpeptidase (79 IU/1). An intravenous pyelogram revealed a normal right 


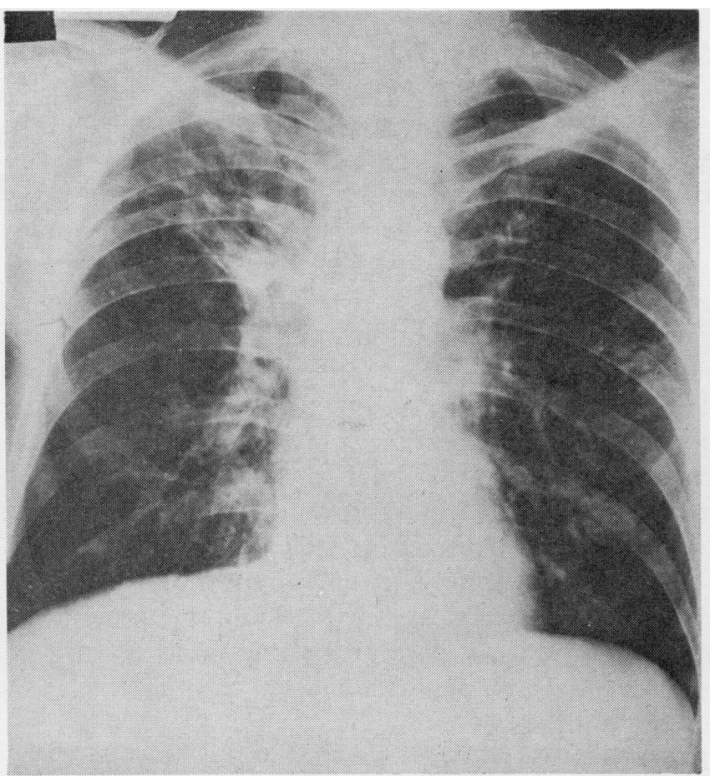

Fig 2 Patient 3. Chest radiograph showing bilateral nodular opacities and segmental consolidation of right upper lobe.

kidney but the chest radiograph showed bilateral nodular opacities and consolidation in the posterior segment of the right upper lobe (fig 2) At bronchoscopy a fleshy tumour was seen in this segment and biopsy showed it to be a clear cell carcinoma. Over the next two years he had recurrent episodes of malaise, fever, and rigors terminated on each occasion by tumour expectoration (fig 3). Microscopy of the material showed clear cell carcinoma (fig 4). Medroxyprogesterone was commenced in February 1979 but discontinued because of cholestasis. The patient deteriorated, and eventually died in September 1979.

\section{Discussion}

Renal carcinoma frequently metastasises to the lungs and such metastases may be present in almost half of all patients at the time of presentation $^{1}$ Typically the tumour spreads by invasion of the renal vein and dissemination through the inferior vena cava, resulting in widespread bloodborne metastases. ${ }^{2}$ Nevertheless, the natural history of the disease may vary greatly and, as in our three patients, even the presence of pulmonary metastases may be compatible with survival for several years. This diversity of behaviour is illustrated by patient 1 , in whom the discovery of

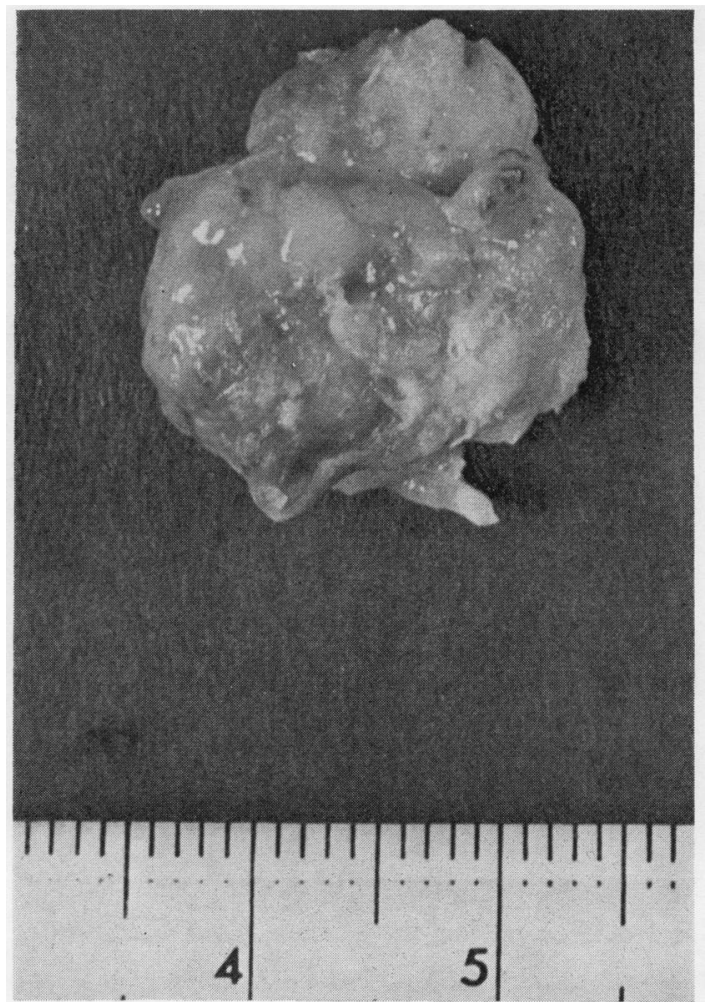

Fig 3 Patient 3. Expectorated tumour tissue. Scale in $\mathrm{cm}$.

metastases preceded that of the renal tumour and who survived a further six years, and patient 3 whose renal tumour was removed 13 years before he developed metastases.

The most striking feature of all three patients was the expectoration of tumour tissue, which was often in the form of ragged bronchial casts. This is the only condition in our combined experience in which casts of such size have been coughed up. Pulmonary metastases occasionally cavitate and the necrotic material may be expectorated, but in our patients the tumour was actually growing up the lumina of bronchi. We assume that the tumour must have been deposited in the bronchial walls by dissemination in the blood via bronchial or pulmonary arteries, and that growth within aircontaining spaces was more easily achieved than growth within solid tissues. It appears that in all cases, in view of the prolonged survival, the body defences and the tumour survival characteristics were finely balanced. It is conceivable that once in bronchial lumina, the tumour cells could have spread by aspiration to other parts of the airways, 


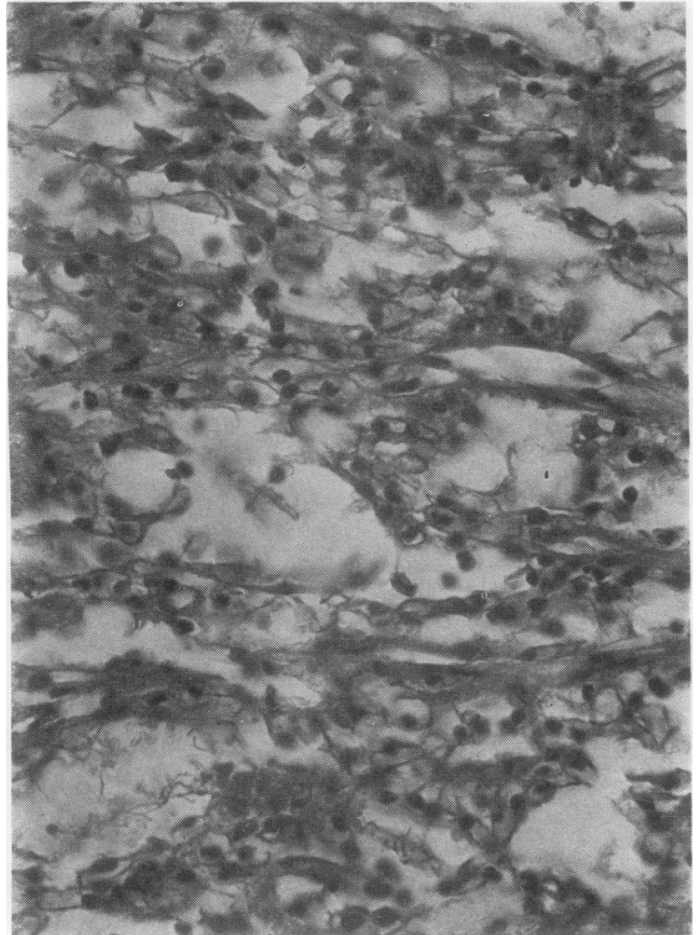

Fig 4 Patient 3. Histological appearances of expectorated tumour showing clear cell carcinoma. $H$ and $E$, original magnification $\times 480$.

as has occasionally been shown in experimental animals. ${ }^{34}$

Gerle and Felson in 1963 described seven patients with intrabronchial metastasis from renal carcinoma." Four of these patients presented with pulmonary symptoms and died of pulmonary and bronchial metasases, and one expectorated tumour tissue. These authors also reviewed 10 other reported cases of bronchial metastases from hypernephroma, in two of which tumour expectoration occurred. ${ }^{6} 7$ They also made the point that the mean time between nephrectomy for the primary tumour and presentation with bronchial symptoms was almost five years in the 10 reported patients who presented in this sequence.
A feature of two of our patients was a febrile illness lasting several days before the tumour was expectorated. Such symptoms are frequently present in patients with renal carcinoma but in our cases they were relieved by production of the tumour. It seems likely that these symptoms were caused by infection distal to the tumour, though they could have been related to necrosis of tumour cells.

While multiple endobronchial metastases are seen occasionally, they usually occur as small discrete foci, often from primary bronchial or alveolar cell tumours. Laryngeal and basal cell carcinoma have also been described as spreading in this way. ${ }^{8}$ Large tumour masses growing loosely in the bronchi and able to be expectorated must be exceedingly rare. When they do occur, our experience and review of the literature suggest that microscopy is likely to show them to contain the large clear cells of renal carcinoma.

\section{References}

1 Murphy GP, Schirmer HK. The diagnosis and treatment of hypernephroma. Geriatrics 1963; 18:354-60.

2 Patel NP, Lavengood RW. Renal carcinoma: natural history and results of treatment. J Urol 1978; 119:722-6.

3 Furth J. Experiments on spread of neoplastic cells through respiratory passages. Am J Pathol 1946; 22:1101-7.

4 Epstein SS. Lung as a transplant site for malignant tumors in rodents. Cancer 1966; 19:454-7.

5 Gerle R, Felson B. Metastatic endobronchial hypernephroma. Dis Chest 1963; 44:225-33

6 Maytum CK, Vinson PP Pulmonary metastasis from hypernephroma, with ulceration into a bronchus simulating primary bronchial carcinoma Arch Otolaryngol 1936; 23: 101-4.

7 Seiler HH, Clagett OT, McDonald JR. Pulmonary resection for metastatic malignant lesions. J Thorac Surg 1950; 19:655:75.

8 Von Zalka E. Uber Aspirations-(Implantations) - Metastasen in den Bronchien und der Lunge in Falle von Kehlkopfkrebs. Arch Ohren, Nasen, Kehlkopfheilk 1934; 138:164-9.

9 Pickren JW, Katz AD. Aspiration metastases from basal cell carcinoma. Cancer 1958; 11:783-9. 